\title{
Immunohistochemical evaluation of oestrogen receptors $\alpha$ and $\beta$ in epithelium of the vaginal mucous membrane in women after oestrogen therapy
}

\author{
Beata Sawczuk ${ }^{1}$, Maria Gołębiewska ${ }^{1}$, Andrzej Mazurek ${ }^{2}$, Lech Chyczewski ${ }^{3}$ \\ ${ }^{1}$ Department of Prosthetic Dentistry, Medical University in Bialystok, Poland \\ ${ }^{2}$ Department if Gynecology, Medical University in Bialystok, Poland \\ ${ }^{3}$ Department of Medical Pathomorphology, Medical University in Bialystok, Poland
}

\begin{abstract}
Oestrogens act on target cells through $\alpha$ and $\beta$ receptors (ER $\alpha$ and ER $\beta$ ). Expression of oestrogen receptors is associated with the age and menopausal condition of women.

The aim of the study was an immunohistochemical evaluation of $E R \alpha$ and $E R \beta$ receptors in epithelium of the vaginal mucous membrane of women subjected to different forms of hormonal therapy (HTM).

Oestrogen receptors $E R \alpha$ and $E R \beta$ were identified using immunohistochemical methods and evaluated in smears of vaginal mucous membranes collected from 60 patients subjected to HTM (including 20 patients after oral therapy, 20 patients after transdermal therapy, and 20 patients after vaginal therapy). The results showed a significant change in immunoreactivity of both studied receptors after three months of hormone therapy. The biggest differences in the changes of intensity of $E R \alpha$ and $E R \beta$ reactions were observed in patients subjected to vaginal therapy. Immunostaining for $\alpha$ receptor showed differences between three types of hormone therapy. The highest increase in the overall intensity occurred after three months of topical therapy. Immunostaining for $\operatorname{Er} \beta$ also varied for different types of hormone therapy.

The results indicate that hormone therapy administered vaginally is the most effective in the treatment of urogenital ailments during menopause. In addition, topical therapy eliminates adverse effects of systemic oestrogen.
\end{abstract}

Key words: oestrogen receptors (ER $\alpha$ and $E R \beta)$, vaginal mucous membrane, menopause.

\section{Introduction}

Menopause in women initiates a period characterised by a number of changes caused by a physiological deficiency of oestrogens. Vaginal epithelium undergoes thinning, the cells become flattened, their content of glycogen is reduced, and epithelial-connective papillae disappear. The $\mathrm{pH}$ increase that accompanies these processes leads to recurrent vaginal infections and infections of the lower urinary tract. The vagina becomes susceptible to injuries. Frequent symptoms reported by patients include irritation, vaginal discharge, painful intercourse, and bleeding. These changes have a negative impact on women's quality of life. The results of experimental, clinical, and epidemiological studies suggest benefits of hormone replacement therapy in menopause $[1,2]$. The benefits of this therapy and associated complications are analysed in terms of location, expression, and function of oestrogen receptors in various tissues and organs. For a number of years it had been thought that there was only one form of oestrogen receptor through which oestrogens could affect the cells.
In 1966 the presence of a new form of oestrogen receptor was demonstrated in rat prostate cells [3]. The previously known and characterised receptor protein was defined as $E R \alpha$, while the latter one was defined as Er $\beta$. In the woman's body both types of receptors occur and they differ in structure, concentration, and location. $E R \alpha$ receptor occurs most frequently in the uterus, ovaries, oviducts, mammary gland, aorta, kidneys, adrenal glands, pituitary gland, hypothalamus, liver, fibroblasts, and macrophages [4]. ER $\beta$ receptor occurs in the ovaries, central nervous system, and circulatory, immune, genitourinary and respiratory systems [5]. Many authors believe that ER $\beta$ receptor dominates in women's reproductive system during the child-bearing period [5-7].

During menopause the quantity of oestrogens is reduced, leading to numerous symptoms in oestrogendependent tissues, i.e. tissues rich in oestrogen receptor. The use of menopausal hormone therapy (HTM) is based on replacing natural ovarian function by administration of oestrogens or progesterone in minimum effective doses. Oestrogens are usually administered 
using oral, transdermal, and vaginal routes. The advantages of oral therapy include its ease of use, a possibility to correct the dose, good drug tolerance, and the possibility to quickly stop the therapy. The disadvantages include an increased concentration of the drug immediately after administration, and its worse absorption in the case of small intestine diseases or antibiotic therapy. Transdermal therapy allows bypassing of the liver in the first step, and also elimination of adverse symptoms of irritation in the gastrointestinal duct. The idea for the topical therapy is the urogenital effect of hormonal drugs with a minimal systemic effect [1].

The aim of this study was a qualitative and quantitative assessment of oestrogen receptors in epithelium of the vaginal mucosa in women subjected to different forms of hormonal therapy.

\section{Material and methods}

The study was conducted using material collected from 60 patients of the Gynaecology Clinic of the University Clinical Hospital in Bialystok. Smears from the mucous membrane of the vagina side wall were collected from 20 patients (mean age 52.9 years) subjected to oral HTM, 20 patients (mean age 53.25 years) subjected to transdermal therapy, and 20 patients (mean age 59.7 years) subjected to vaginal therapy.

The study protocol was approved by the Ethics Committee at the Medical University of Bialystok (No1-003/442/2004/2005), and written informed consent was obtained from each woman. Patients were qualified for HTM based on their history and clinical examination. The examined patients did not report any organ ailments and did not take any other medications. The patients received the following oestradiol formulations: tablets administered orally (1 mg oestradiolum $+2 \mathrm{mg}$ drospirenonum once a day), patches applied transdermally $(50 \mu \mathrm{g}$ oestradiolum and $170 \mu \mathrm{g}$ norethisterone acetate in a skin patch, one patch for three days), and vaginal globules applied topically ( $0.5 \mathrm{mg}$ oestradiolum once a day).

\section{Light microscopy}

Four smears before the treatment and four smears after three months of menopausal oestrogen therapy were collected from each patient using a brush (Cervex- Brush Rovers, Netherlands). The material was applied to silanised microscope slides (Comex, Poland), fixed with Cytofix (Samko), and processed using immunohistochemical methods for the detection of $\alpha$ and $\beta$ oestrogen receptors.

\section{Immunohistochemical procedure}

The ABC method according to Hsu et al. (1981) was used. The slides were rinsed with Tris buffer $(\mathrm{pH} 7.4)$, and subsequently the smears were incubated with $0.3 \%$ hydrogen peroxide in methanol to block endogenous peroxidase activity: 30 minutes for $E R \alpha$ and 10 minutes for ER $\beta$. The smears were incubated at room temperature in a humidified chamber with the primary antibodies ER $\alpha$ (VP-E617) and ER $\beta$ (VP-E615) (Vector Laboratories, Inc., 30 Ingold Road, Burlingame, CA 94010, U.S.A.). The incubation time was 60 minutes for $E R \alpha$ and 26 hours for ER $\beta$. The Er $\alpha$ antibody was used at a concentration of 1:80, and the anti-ER $\beta$ at a concentration of $1: 25$. The detection of bound antibodies was performed using a Vectastain Universal ABC kit (PK-4000, Vector Laboratories, Inc., 30 Ingold Road, Burlingame, CA 94010, U.S.A.).

To visualise the antigen-antibody reaction a Liquid DAB Substrate kit (Novocastra Laboratories Ltd, UK) was used. Finally, the smears were counterstained with haematoxylin QS (H 3404; Vector Laboratories, Inc., 30 Ingold Road, Burlingame, CA 94010 U.S.A.), subjected to dehydration in ethanol gradient $(70 \%, 96 \%, 99.9 \%)$ and xylene, and covered with Canada balsam. The reactions were performed in accordance with the procedures indicated by the manufacturer of antibodies.

The smears from the vaginal mucous membranes were analysed by means of optical microscopy (Olympus BX41) and photographed. In each case, photographs of five areas were analysed for the presence of protein (stained dark brown) in the nuclei as well as in the cytoplasm of epithelial cells. The assessment of the histological pattern was conducted in a semi-quantitative way, using an immunoreactivity score. A histological comparative quantification of immunolabelling of the smears before the therapy and after three months of oral, transdermal, and topical hormone therapy was performed for each of the two antibodies (ER $\alpha$ and $E R \beta)$. Receptor expression intensity was assessed, by evaluating coloured reaction products, in the nuclei of 200 different cells, in each sample, at different views. We divided the results into groups with high intensity of receptor expression in the cell nucleus (intensity 3), medium intensity of receptor expression (intensity 2), low intensity of receptor expression (intensity 1), and no receptor expression (intensity 0 ). We quantified the number of cells with different intensity of expression in each view and performed statistical analysis by Kolmogorov-Smirnov test.

\section{Results}

Positive immunohistochemical reactions for both $E R \alpha$ and $E R \beta$ receptors were observed in all vaginal smears collected from the studied women.

Immunostaining for $\alpha$ receptor showed differences between the three types of hormone therapy (Fig. 1). Cell labelling was usually observed in the nuclei, and only occasionally in the cytoplasm. In oral therapy, epi- 


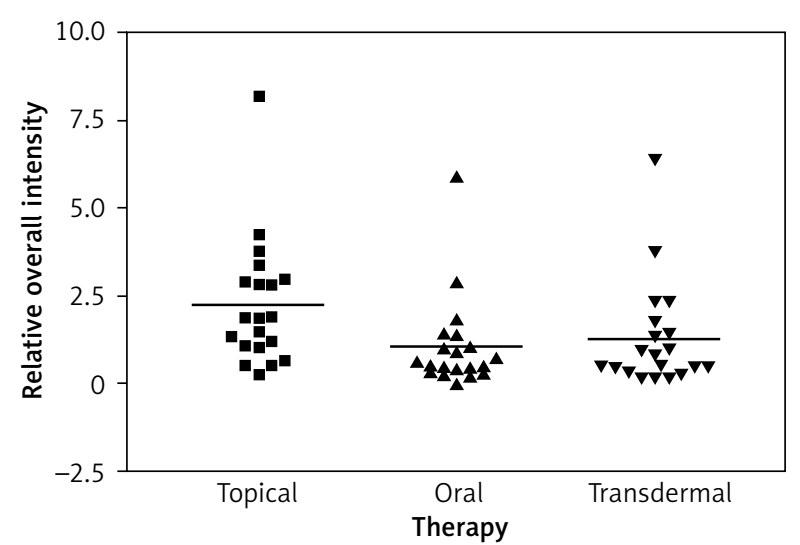

Fig. 1. Impact of the therapy on relative overall intensity of Era expression in vagina after 3 months

thelial immunostaining was slight or limited to scattered nuclei (Figs. 2, 3A, B). In transdermal therapy the mean intensity value equalled 0.2 , and in topical hormone therapy the mean intensity value equalled 0.4 (Figs. 3B, C, 4, 5). The highest increase in the overall intensity occurred after three months of topical therapy (an increase from 0.2 to 0.4 ), while the lowest increase was observed for oral therapy (from 0.12 to 0.2 ). In topical hormone therapy epithelial immunostaining was more intense than in transdermal and oral hormone therapies. Immunostaining for $\operatorname{Er} \beta$ also varied for different types of hormone therapy (Fig. 6). The average value of overall intensity in oral therapy equalled 0.8 (Fig. 7). In transdermal therapy the average value of overall intensity equalled 0.41 (Fig. 8). After using a topical hormone therapy, the presence of the receptor was observed in the majority of the nuclei of epithelial cells (Figs. 9, 10E, F). The average value of overall intensity equalled 0.75 and showed the highest (compared to other forms of therapy) increase in ER $\beta$ activity after three months of therapy.

\section{Discussion}

Menopause initiates a period of numerous changes caused by physiological oestrogen deficiency. A normal level of hormones determines the induction of epithelial cell proliferation, which prevents urogenital atrophy [8]. A series of studies on the location of ER $\alpha$ and ER $\beta$ in the female reproductive system has been conducted $[4-6,9,10]$. Previously published research results concerning the occurrence and distribution of oestrogen receptors are not consistent. Pelletier [6] identified only $E R \alpha$ in the epithelium and lamina propria of the vaginal mucous membrane, and in smooth muscle cells of women in their reproductive period. However, in other studies of Taylor et al. [5], concerning the evaluation of ER $\beta$ expression in cells of different organs, the presence of $\beta$ receptor was revealed, also in female vaginal cells. The highest expression of

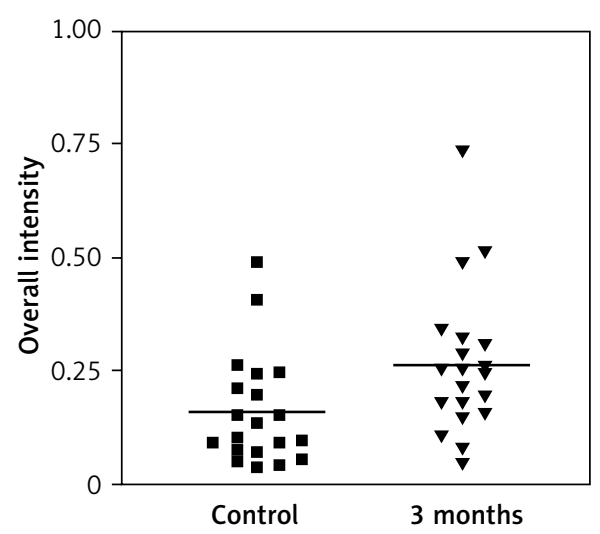

Fig. 2. Impact of time on overall intensity of Era expression after using oral therapy

this receptor was observed in nuclei, while within the cytoplasm it was much lower. In the studies related to the evaluation of oestrogen receptors expression in women at different stages of life, Cavallini [11] revealed the presence of both types of receptors both before and after menopause, with a clear dominance of $E R \alpha$ in vaginas of the investigated women. However, no significant difference in expression of this receptor before and after menopause was observed. In this study Cavallini reported at the same time a significant decrease in ER $\beta$ expression after menopause, as compared to women before menopause. The research results obtained by other authors confirm the presence of ER $\alpha$ in women before and after menopause, and the presence of ER $\beta$ in the vagina before menopause, as well as its disappearance during menopause [12]. The results presented in this study confirm the presence of both $\alpha$ receptor and $\beta$ receptor in vaginal epithelium of menopausal women before and after oestrogen therapy. Immunodetection revealed the presence of receptor proteins predominantly in the nucleus, and only occasionally in the cytoplasm of tested cells. Literature reports regarding the changes in the level of oestrogen receptors present in the vagina as a result of hormone therapy are scarce, and the presented results are controversial. Discrepancies between the results may be caused by different test methods, the health condition, or age of the investigated women. In comparative studies conducted by Gebhart et al. [7] in patients before and after menopause using oral and transdermal hormone therapy, and in women who did not use HTM, the highest expression of ER $\alpha$ and ER $\beta$ was observed in the vaginas of women before menopause, while a slightly lower expression was observed in the vaginas of women after menopause, who did not use HTM. The patients who used HTM had lower expression levels of both receptors, as compared to women who were not subjected to hormone therapy. Moreover, the authors found that in women subjected to hormone therapy expression of $E R \alpha$ was much stronger in comparison 

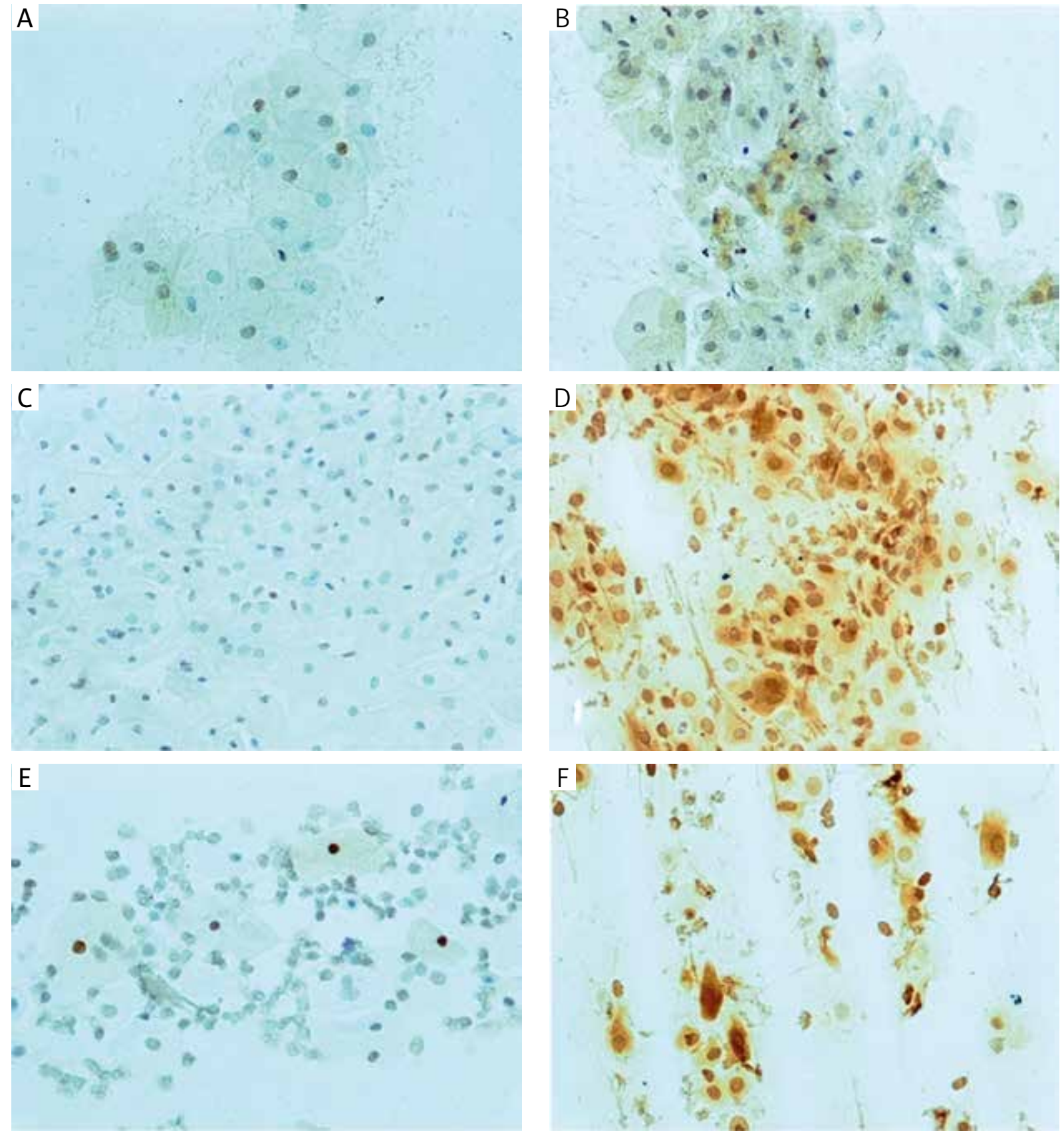

Fig. 3. Ero-immunoreactivity in the vaginal epithelium, before and after three months of therapy: A, B - oral, C, D - transdermal and E, F-topical. Original magnification 200x

to $E R \beta$. In the present study, in contrast to the results presented in the above study, the change of the immunoreactivity of both oestrogen receptor types dependent on the form of treatment was observed. The highest increase in the ER $\alpha$ and $E R \beta$ intensity was observed in patients subjected to topical therapy, while in patients applying oral and transdermal therapy it was significantly lower. The results obtained in the conducted studies indicate the highest effectiveness of topical therapy in stimulating oestrogen receptors present in the epithelium of vaginal mucous membrane. The effect of topical treatment on $\mathrm{pH}$ change in the vagina was also confirmed by Maloney et al. [13], who investigated 258 postmenopausal women subjected to 12 -week vaginal oestrogen therapy. As early as after six weeks the vaginal $\mathrm{pH}$ decreased from 7.41 to 6.8 . The obtained results led to a conclusion that topical oestrogen therapy may be effective in the treatment of urogenital ailments. The effectiveness of vaginal oestrogen therapy in alleviating urogenital ailments was also confirmed by the studies of Cardozo et al. [14] concerning the impact of oestrogen therapy on the genitourinary system of older women. The present results revealed that epithelial immunostaining for both 


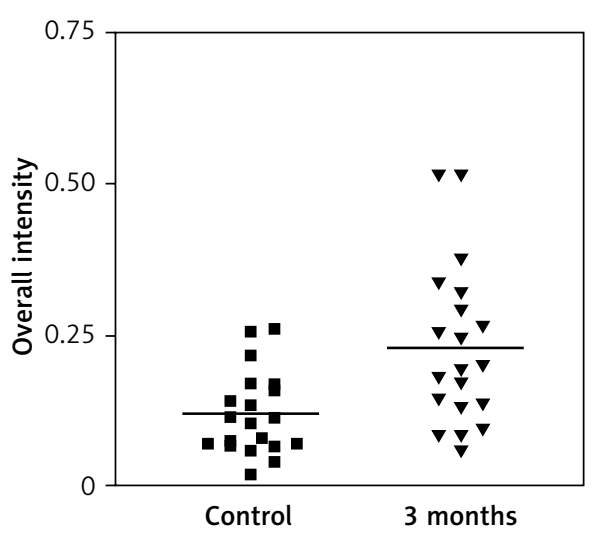

Fig. 4. Impact of time on overall intensity of Era expression after using transdermal therapy

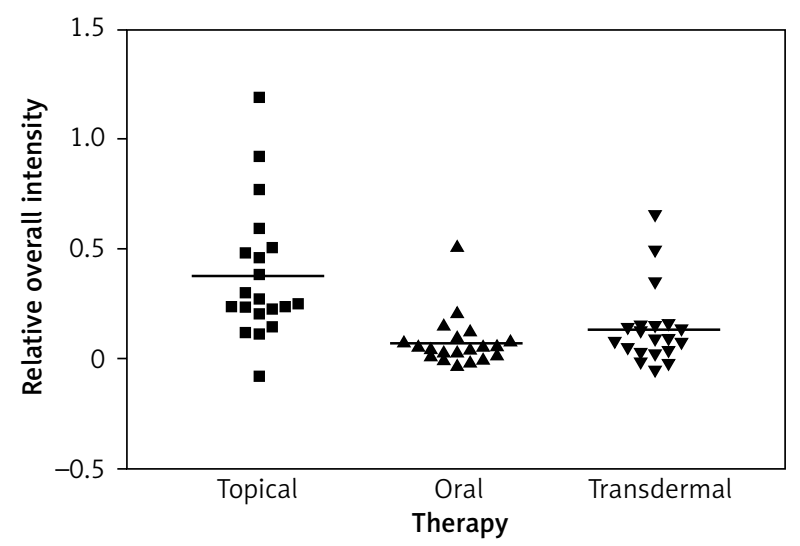

Fig. 6. Impact of the therapy on relative overall intensity of $\operatorname{Er} \beta$ expression in vagina after 3 months

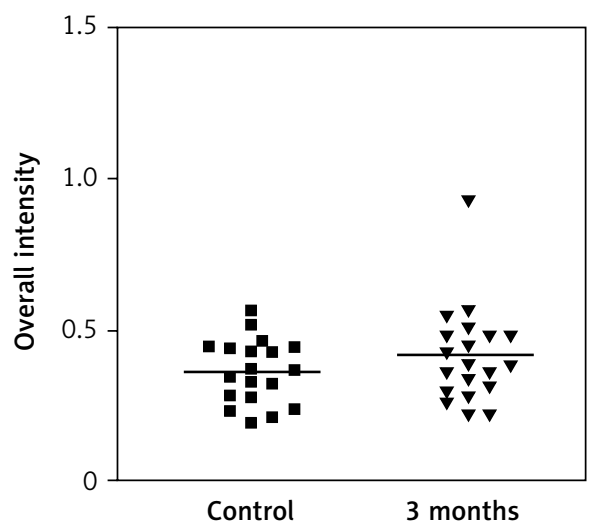

Fig. 8. Impact of time on overall intensity results of $\operatorname{Er} \beta$ expression in vagina for transdermal

$E R \alpha$ and $E R \beta$ is the most intense after vaginal oestrogen therapy. To conclude, the obtained data indicate that oestrogen action in the vagina is mediated by $E R \alpha$ and ER $\beta$ present in the epithelium. The current study showed a significant difference in the expression intensity of $\beta$ receptors in the epithelium after topical oestrogen therapy, as compared to the baseline. In summary, the present study showed the presence of $\alpha$ and $\beta$ receptors, with higher $\beta$ expression and high-

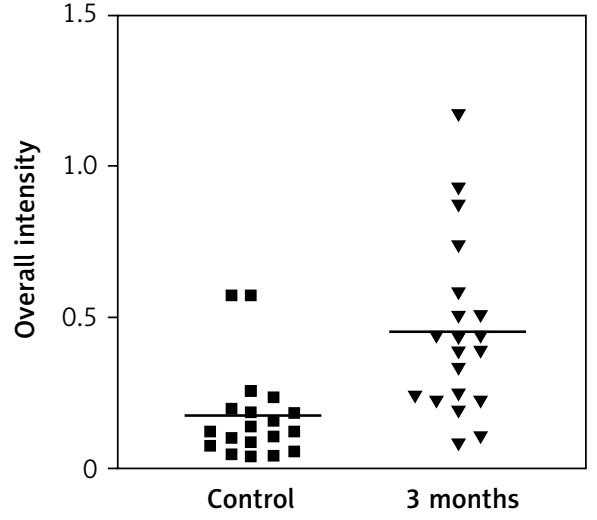

Fig. 5. Impact of time on overall intensity of Era expression after using topical therapy

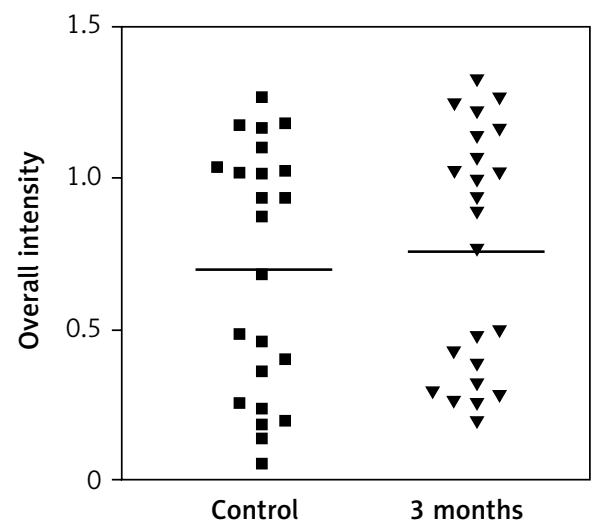

Fig. 7. Impact of time on overall intensity results of $\operatorname{Er} \beta$ expression in vagina for oral therapy

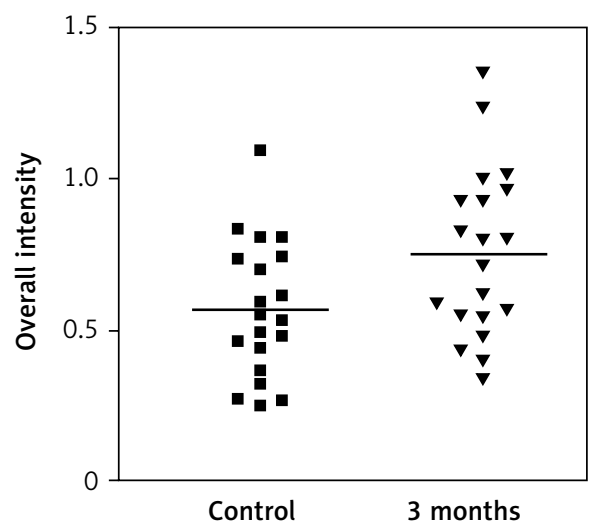

Fig. 9. Impact of time on overall intensity results of $\operatorname{Er} \beta$ expression in vagina for topical

er intensity in the epithelium after topical oestrogen therapy. The presence of oestrogen receptors in genitourinary organs indicates the obvious connection of sex hormones and atrophic changes both within the reproductive organs, and in the lower urinary tract. The results may confirm beneficial effects, especially of topical oestrogenotherapy on menopausal changes in the urinary system. In addition, topical therapy eliminates adverse effects of systemic oestrogen. 

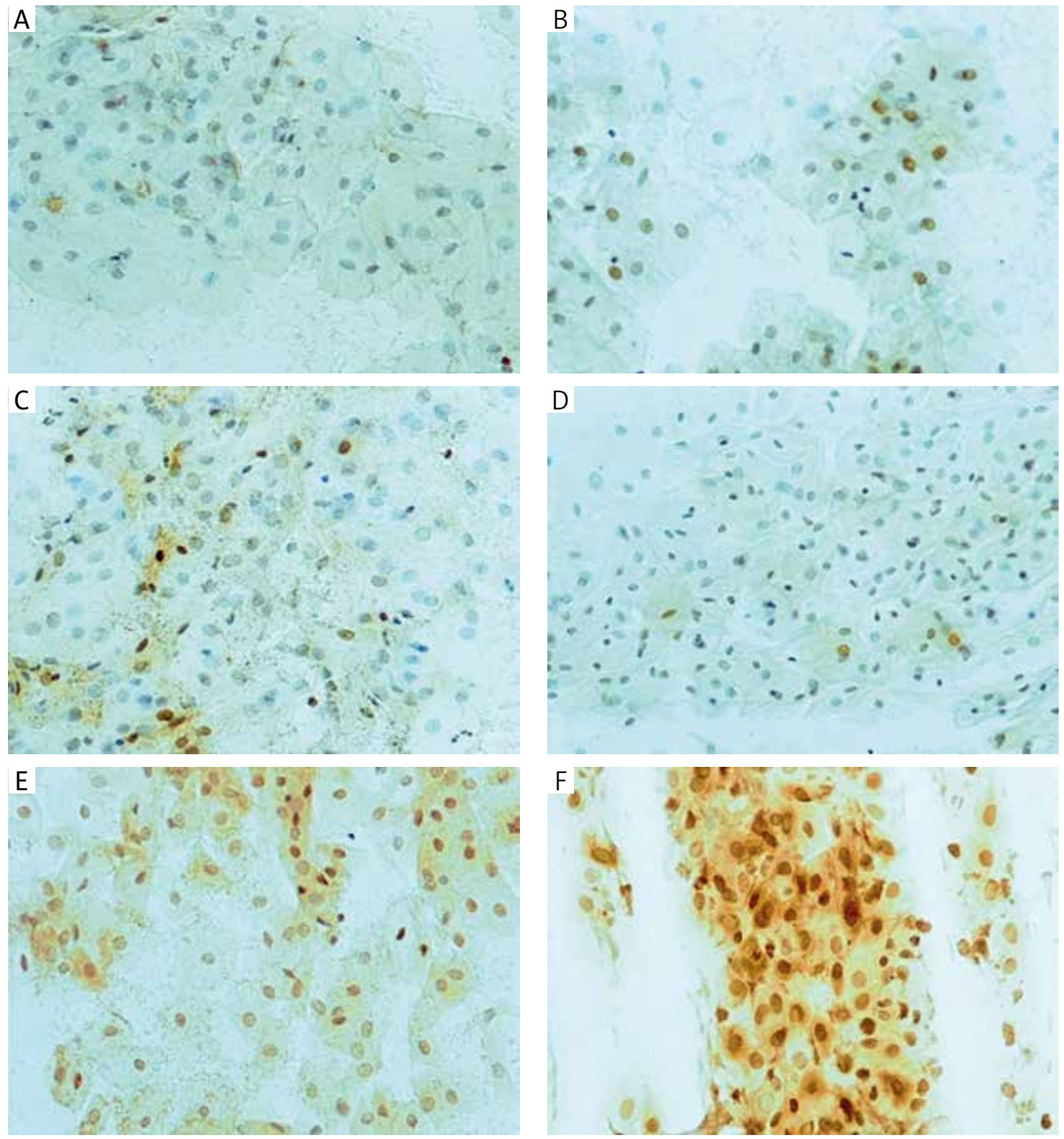

Fig. 10. Er $\beta$-immunoreactivity in the vaginal epithelium, before and after three months of therapy: A, B - oral, C, D - transdermal and E, F- topical. Original magnification 200x

\section{Disclosure}

Authors report no conflict of interest.

\section{References}

1. Jakowicki J. Klimakterium. Hormonalna terapia zastępcza. Poradnik terapeutyczny. Biofolium, Lublin 2001

2. Skałba P. Hormonalna terapia zastępcza. Wyd. Lek. PZWL, Warszawa 2005.

3. Toft D, Gorski J. A receptor molecule for estrogen: Isolation from rat uterus and preliminary characterization. Proc Nat Acad Sci U S A 1966; 5: 1574-1581.
4. Laszczyńska M, Starczewski A, Karakiewicz B, Brodowski J. The localization of estrogen receptor alpha and its function in ovaries of postmenopausal women. Folia Histochem Cytobiol 2007; 45: 325-330.

5. Taylor AH, Al-Azzawi F. Immunolocalisation of oestrogen receptor beta in human tissues. J Mol Endocrinol 2000; 24: 145-155.

6. Pelletier G, El-Alfy M. Immunocytochemical localization of estrogen receptors alpha and beta in the human reproductive organs. J Clin Endocrinol Metab 2000; 85: 4835-4839.

7. Gebhart J, Rickard D, Barett T. Expression of estrogen receptor isoforms alpha and beta messenger RNA in vaginal tissue of premenopausal and postmenopausal women. Am J Obstet Gynecol 2001; 185: 1325-1330.

8. Pschyrembel W, Strauss G, Petri E. Ginekologia praktyczna. Wyd. Lek. PZWL, Warszawa 1994 
9. Piekarski J. Receptory estrogenowe i progesteronowe w raku piersi współczesny stan wiedzy. Współcz Onkol 2005; 9: 391-379.

10. King R, Gordon J, Martin L. The association of $(6,7-\mathrm{H} 2)$ oestradiol with nuclear chromatin. Biochem J 1965; 97: 28-32.

11. Cavallini A, Dinaro E, Giocolano A. Estrogen receptor and Er-related receptor expression in normal and atrophic human vagina. Maturitas 2008; 59: 219-225.

12. Chen G-D, Oliver R, Leung B. Estrogen receptor alpha and beta expression in the vaginal walls and uterosacral ligaments of premenopausal and postmenopausal women. Fertil Steril 1999; 71: 1099-1102.

13. Maloney C, Oliver ML. Effect of local conjugated estrogens on vaginal $\mathrm{pH}$ in elderly women. J Am Dir Assoc 2001; 2: 51-55.

14. Cardozo L, Bachmann G, McClish D, et al. Meta-analysis of estrogen therapy in the management of urogenital atrophy in postmenopausal women: second report of the Hormones and Urogenital Therapy Committee. Obstet Gynecol 1998; 92: 722-727. 